\title{
From barriers to limits to climate change adaptation: path dependency and the speed of change
}

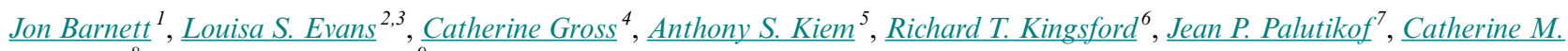 \\ Pickering $^{8}$ and $\underline{\text { Scott G. Smithers }}{ }^{9}$
}

\begin{abstract}
Research on the barriers and limits to climate change adaptation identifies many factors, but describes few processes whereby adaptation is constrained or may indeed fail to avoid catastrophic losses. It often assumes that barriers are by and large distinct from limits to adaptation. We respond to recent calls for comparative studies that are able to further knowledge about the underlying drivers of barriers and limits to adaptation. We compare six cases from across Australia, including those in alpine areas, rivers, reefs, wetlands, small inland communities, and islands, with the aim of identifying common underlying drivers of barriers and limits to adaptation. We find that the path-dependent nature of the institutions that govern natural resources and public goods is a deep driver of barriers and limits to adaptation. Path-dependent institutions are resistant to change. When this resistance causes the changes necessary for adaptation to be slower than changes in climate, then it becomes a limit to adaptation.
\end{abstract}

Key Words: communities; cultures; ecosystems; markets; path dependence; transformation; values

\section{INTRODUCTION}

Under even modest rates of global warming, adaptation may not avoid harm to social and ecological systems (Adger et al. 2009a, Meinshausen et al. 2009, Stafford-Smith et al. 2011). Much depends on the severity of the climatic perturbation and the sensitivity and resilience of the systems at risk (Dow et al. 2013a). Concepts of barriers and limits often frame research on how adaptation is constrained by various social and biophysical factors, or may fail to avoid catastrophic climate impacts.

The concepts of barriers and limits to adaptation became widely used after their inclusion in the Intergovernmental Panel on Climate Change (IPCC) Fourth Assessment Report chapter on adaptation (Adger et al. 2007). Subsequent research justified a chapter titled "Adaptation Opportunities, Constraints, and Limits" in the IPCC Fifth Assessment Report (Klein et al. 2014). Understanding where, when, and how barriers and limits to adaptation arise has become an important frontier in climate change research (Adger et al. 2009a, 2009b, Stafford-Smith et al. 2011, Dow et al. 2013a, 2013b, Islam et al. 2014, Palutikof et al. $2014 a$ ). Two recent reviews argue that advances in knowledge require comparative studies that seek to identify the underlying drivers of the barriers and limits to adaptation (Biesbroek at al. 2013, Eisenack et al. 2014). We seek to produce new knowledge about barriers and limits to adaptation by comparing six cases of adaptation from across Australia, aiming to identify common underlying drivers of these barriers and limits.

\section{THE INTERPLAY BETWEEN BARRIERS AND LIMITS}

Adaptation is an ongoing process of adjusting to changes, with no end point. This means that defining successful adaptation is more about the sustainability of processes and the principles of fairness and equity than it is about measuring outcomes at any given point in time (Stafford-Smith et al. 2011, Hurlimann et al.
2014). Successful adaptation is therefore a matter of "socially and environmentally sustainable development pathways, including both social justice and environmental integrity" (Eriksen et al. 2011:8). There are many definitions, synonyms, and typologies of barriers that impede adaptation (Biesbroek et al. 2013). We define barriers to adaptation as obstacles that can be overcome with concerted effort (sensu Moser and Ekstrom 2010), and we define limits to adaptation as the points at which adaptation actions fail to protect things that stakeholders value (sensu Adger et al. 2009a).

Most definitions of barriers to adaptation identify them as factors that impede adaptation, but that are surmountable with effort. The evidence and theory about barriers that impede adaptation include a vast array of factors, grouped predominantly by the disciplinary and theoretical predilections of researchers. The IPCC provides a systematic typology of barriers (called constraints), including knowledge, awareness, and technology; the physical environment; biological tolerances; economic factors; financial factors; human resources; social and cultural factors; and governance and institutional processes (Klein et al. 2014). They note that underlying many of these issues are competing values, which necessitate trade-offs in prioritizing adaptation actions. The barriers to adaptation are context specific; indeed Eisenack and colleagues (2014) define them in terms of impediments to specific actions necessary to meet the goals of specific actors, which underscores the problem of tradeoffs among competing goals in adaptation decisions.

Given that context matters, evidence about barriers to adaptation in Australia is important for our study. Within Australia, there has been a good deal of research on barriers to adaptation to sealevel rise in primary industries and local governments. Commonly identified barriers include a lack of or inconsistent leadership, insufficient knowledge of risks and responses, inadequate

${ }^{1}$ School of Geography, University of Melbourne, ${ }^{2}$ Geography, College of Life and Environmental Science, University of Exeter, ${ }^{3}$ Australian Research Council Centre of Excellence for Coral Reef Studies, James Cook University, ${ }^{4}$ Fenner School of Environment and Society, Australian National University, ${ }^{5}$ School of Environmental and Life Sciences, University of Newcastle, ${ }^{6}$ School of Biological, Earth and Environmental Sciences, University of New South Wales, ${ }^{7}$ National Climate Change Adaptation Research Facility, Griffith University, ${ }^{8}$ School of Environment, Griffith University, ${ }^{9}$ College of Marine and Environmental Sciences, James Cook University 
funding, difficulties in negotiating among competing values and goals, a lack of institutional support, and poor coordination across levels of government (McDonald 2007, Preston et al. 2008, Smith et al. 2008, Measham et al. 2011, Scally and Wescott 2011, Macintosh 2012, Mukheiber et al. 2013, Raymond and Robinson 2013, Hodgkinson et al. 2014, Hurlimann et al. 2014, Macintosh et al. 2014, Marshall and Stokes 2014a). A recent analysis of 79 submissions from industry, government, and civil society organizations to a national inquiry on barriers to climate change adaptation also concluded that governance and tensions around competing policy priorities were seen by most actors to be the major barrier to adaptation (Waters et al. 2014). A lack of clarity on roles and responsibilities of the three levels of Australian government, and of the private sector versus the public sector, was seen as a major impediment.

One of the deep drivers of barriers to adaptation in Australia, and in many other countries, appears to be path dependency (Burch 2010, Garrelts and Lange 2011, Inderberg 2011, Eckstom and Moser 2014). History shapes current decisions, and the changes identified for adaptation are impeded because they work against existing governance institutions. Path dependency manifests as resistance to changing the way things have always been done, even if business as usual seems to be increasingly maladaptive. It also manifests as resistance to doing things that have never been done or to improving deficient practices. This latter point speaks to much of the problem of social vulnerability to climate change, which arises because important basic freedoms and opportunities such as primary education for girls or social protection in times of crisis are not provided for reasons of ignorance or prejudice (Barnett 2009). Of course, path change is always possible (Garrelts and Lange 2011), but if it does not commence for a protracted period or progresses more slowly than climate change, then path dependency may best be described as a deeper cause of limits to adaptation.

Indeed, the distinction between barriers and limits to adaptation is ambiguous. Many of the theorized limits to adaptation are social constructions in two senses. First, they arise because social processes expose groups to climate change risks, constrain their adaptive capacities, or impede adaptation responses. Second, the things that stakeholders value, at risk of loss or damage, are themselves the product of shared meanings (Adger et al. 2009a, Dow et al. 2013b). Because vulnerability and adaptation are in this sense in the eye of the beholder, understanding the perspective of actors is necessary to understand how and for whom adaptation is constrained and limited (Eisenack et al. 2014). This socially constructed nature of many barriers and causes of limits to adaptation suggests that societal transformations are necessary for managing climate change. It may be only through changes of large magnitude that the social processes that impede or limit adaptation or the shared meanings of what is at risk can be changed (Park et al. 2012, Rickards 2013, Klein et al. 2014).

Many of the theorized limits to adaptation have ambiguous status as both barrier and limit. For example, the oft-mentioned economic limits to adaptation (Adger et al 2009a, Klein et al. 2014) may be reached when the costs of adaptation exceed the costs of impacts averted. This depends on many factors, including if, and how, nonmarket impacts are included in the evaluation and on the choice of discount rates applied (Fankhauser 2010).
Depending on how these are resolved, economic factors may impede adaptation but may be tractable with concerted effort (i.e., operating as barriers), or they may be simply too great and the price of adaptation may never be paid (i.e., operating as limits). Further, even assuming that some agreed-on estimate of costs and benefits is possible, agreement on who should pay the costs often remains a significant social problem.

As some barriers can become limits, so some limits to adaptation can potentially be overcome and transformed into barriers with new cultures, values, technologies, or governance systems. Thus, socially determined limits to adaptation are sometimes referred to as "soft" limits (Dow et al 2013b, Klein et al 2014). These contrast with "hard" limits that arise when species, communities, or ecosystems cannot adjust to new climate regimes in time to avoid degradation or collapse, as with coral reefs affected by ocean warming and acidification (Veron 2011). Knowledge about these hard limits to adaptation is more advanced than the more socially contingent and dynamic soft limits.

Therefore, there is significant if seldom acknowledged interplay between barriers and limits to adaptation. Time and path dependence can change some perceived barriers into limits as it becomes apparent that they will not be overcome. Conversely, transformations in institutions, values, and technologies may render some factors perceived to cause limits into barriers, because the shared meanings of loss change or the capacity to avoid these losses improves. We explore this interplay through the following six Australian cases, where some adaptation is under way.

\section{APPROACH AND METHODS}

We summarize new knowledge about barriers and limits to adaptation by comparing six cases of adaptation from across Australia. These case studies, the risks climate change poses in each, and a hyperlink to the full report are provided (Table 1).

Case studies were selected according to three key criteria. First, we sought study sites allowing exploration of biophysical and social limits. The Alpine, Great Barrier Reef, and Torres Strait cases were selected because we assumed these would involve hard limits because of the absolute constraints posed by the loss of snow, coral, or shorelines, whereas the wetland and inland cases were initially assumed to involve value trade-offs and governance institutions that caused soft limits. Second, we wanted examples of systems where adaptation was under way, with previous studies and heightened awareness among stakeholders about climate change risks and potential responses. The inland town case was selected because it provided an opportunity to study the barriers and limits to a significant climate change adaptation policy response: water trading. Third, we sought cases where we could ask teams of social and environmental scientists with a history of research association with the location to conduct targeted additional research for the purposes of this project. In selecting teams based on their expertise and experience in the location, we sought researchers who had the deep contextual knowledge of the study areas and the access to key informants that are both necessary for understanding the barriers and limits to adaptation. Finally, we chose iconic cases of considerable environmental or social significance to Australians and sometimes internationally (Fig. 1), providing relevance to an international and interdisciplinary audience. These studies also provided insights into the Australian adaptation experience, which is relevant to a wide audience given that Australia is a wealthy 
Table 1. The six case studies.

\begin{tabular}{|c|c|c|}
\hline Study Area & Climate Change Risks & Report \\
\hline The Australian Alps & $\begin{array}{l}\text { To the survival plants, animals, businesses, } \\
\text { and settlements that depend on winter } \\
\text { snow for their survival. }\end{array}$ & $\begin{array}{l}\text { Morrison and Pickering 2011, } \\
\text { https://www.nccarf.edu.au/publications/ } \\
\text { limits-adaptation-climate-change- } \\
\underline{\text { adaptation-australian-alps }}\end{array}$ \\
\hline The Coorong and Lower Lakes & $\begin{array}{l}\text { To the health of riparian and aquatic } \\
\text { ecosystems and the businesses, } \\
\text { communities, and cultures that depend on } \\
\text { them. }\end{array}$ & $\begin{array}{l}\text { Gross et al. 2011, } \\
\text { https://www.nccarf.edu.au/publications/ } \\
\text { limits-adaptation-coorong-murray- } \\
\underline{\text { alexandrina-albert }}\end{array}$ \\
\hline The Great Barrier Reef & $\begin{array}{l}\text { To the health of the reef and the } \\
\text { businesses, communities, and cultures that } \\
\text { depend on it. }\end{array}$ & $\begin{array}{l}\text { Evans et al. 2011, } \\
\text { https://www.nccarf.edu.au/publications/ } \\
\text { limits-adaptation-great-barrier-reef }\end{array}$ \\
\hline The Macquarie Marshes & $\begin{array}{l}\text { To the health of riparian and aquatic } \\
\text { ecosystems. }\end{array}$ & $\begin{array}{l}\text { Jenkins et al. 2011, } \\
\text { https://www.nccarf.edu.au/publications/ } \\
\text { limits-adaptation-floodplain-wetlands- } \\
\underline{\text { macquarie-marshes }}\end{array}$ \\
\hline $\begin{array}{l}\text { Small inland communities affected by } \\
\text { drought }\end{array}$ & $\begin{array}{l}\text { To the viability of small rural communities } \\
\text { exposed to drought and to market based } \\
\text { adaptation instruments. }\end{array}$ & $\begin{array}{l}\text { Kiem and Austin 2012, } \\
\text { https://www.nccarf.edu.au/publications/ } \\
\text { limits-adaptation-small-inland- } \\
\text { communities-drought }\end{array}$ \\
\hline The Torres Strait Islands & $\begin{array}{l}\text { To the morphology of islands and the } \\
\text { human settlements and cultures that } \\
\text { depend on them. }\end{array}$ & $\begin{array}{l}\text { McNamara et al. 2011, } \\
\text { https://www.nccarf.edu.au/publications/ } \\
\text { limits-adaptation-low-lying-communities- } \\
\text { torres-strait }\end{array}$ \\
\hline
\end{tabular}

Fig. 1. Location of the six case studies.

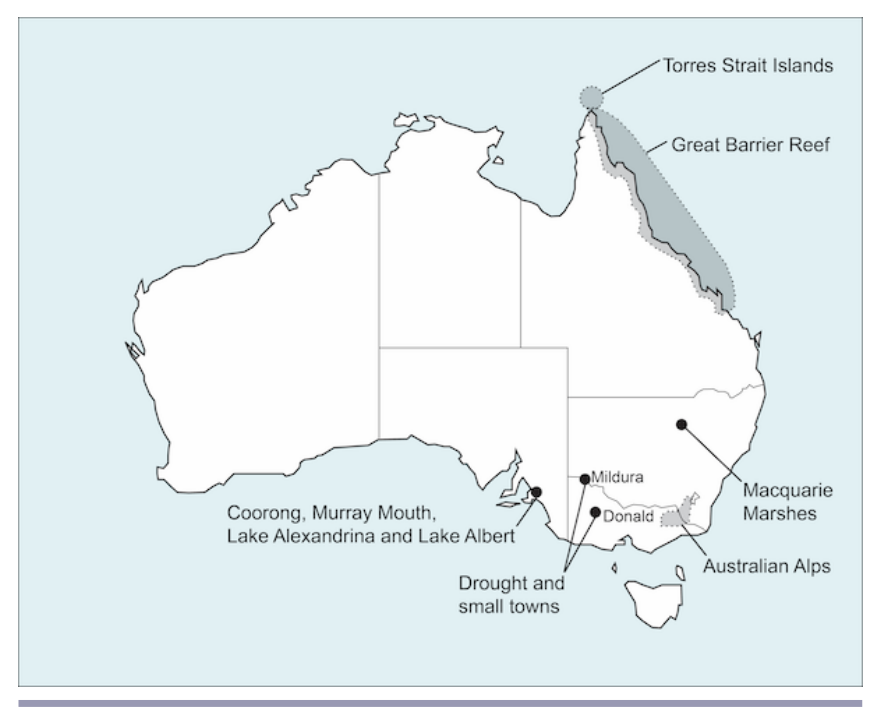

liberal-democratic society exposed to high levels of climate variability. Australia also has a high degree of public awareness and acceptance of climate change, underpinning a large and purposeful investment in climate change science and adaptation research (Palutikof et al. 2014b).

All research teams were asked to identify climate change risks, social and environmental drivers of these risks, adaptation goals and strategies, and the pertinent barriers and limits to these adaptation goals and strategies. This was to be achieved through reviews of existing information about present and future climate risks, other drivers of risk, and adaptation proposals and plans. Some primary data collection, involving key informants and stakeholders, was also conducted to provide new information and insights. Methods for sampling, the sample size, and data collection were not prescribed given the diverse nature of cases and skills of the research teams (see detailed methods in Table 2).

\section{CASE STUDIES}

\section{The Australian Alps}

The goal of adaptation in the Australian Alps is to sustain ecosystems and tourism industries that depend on winter snow, which continues to decline (Morrison and Pickering 2011, 2013a, 2013b).

Regional stakeholders including park agencies, local communities, and the tourism industry are all developing and implementing adaptation strategies. Ecological adaptation by conservation organizations is mainly focused on increasing the resilience of ecosystems by controlling invasive species, rehabilitating disturbed sites, restoring endemic communities and connectivity, providing ex situ conservation of key species, reducing soil erosion, and suppressing fires. These strategies face constraints. For example, management of fire, feral animals, and weeds in National Parks is constrained by the land management practices of surrounding landowners and some tourism practices. There are considerable challenges to current maintenance of the ecological integrity of the Australian Alps under present climatic conditions. Changing climatic conditions, including declining snow cover and increasing fire intensity, will surpass the ability 
Table 2. Methods used in each case study.

\begin{tabular}{ll}
\hline \hline Study Area & Research Methods \\
\hline The Australian & Literature review \\
Alps & Semistructured telephone interviews, $\mathrm{n}=16$ \\
The Coorong & Literature review \\
and Lower & Semistructured face to face interviews, $\mathrm{n}=36$ \\
Lakes & \\
The Great & Literature review \\
Barrier Reef & Scenario development \\
& Stakeholder workshops (2 workshops, 19 \\
& participants) \\
The Macquarie & Semistructured interviews, $\mathrm{n}=7$ \\
Marshes & Climate scenarios and response modeling \\
& Stakeholder workshop (22 participants) \\
Small inland & Semi structured interviews, $\mathrm{n}=5$ \\
communities & Piterature review \\
affected by & Historical climate analysis (observed local climate \\
drought & data) \\
& Semistructured face to face interviews, $\mathrm{n}=35$ \\
The Torres & Scenario planning workshop (15 participants) \\
Ltrait Islands & Semistructured face to face interviews, $\mathrm{n}=28$ \\
\hline &
\end{tabular}

of these strategies to avoid critical thresholds of change in the function and integrity of Alpine ecosystems and associated communities and species. Areas of true alpine ecosystems will probably be lost within the next century, if not sooner.

The main adaptation strategy by the tourism industry is to make more snow to offset declining natural snow cover (Morrison and Pickering 2013a, 2013b). Their other economic adaptation strategies include a short-term focus on increased real estate sales and a long-term focus on diversifying toward year-round tourism. All these strategies have barriers and limits. For example, snowmaking is presently constrained by cost and climatic conditions, which are potentially immutable long-term factors (Pickering and Buckley 2010). The increased demand for water for snowmaking will probably coincide with reduced availability and increasing cost and demand from other sectors, e.g., power. The sector probably has neither the political nor the economic capital to acquire the necessary water. Because it seems unlikely that present economic barriers will be overcome, they will become the cause of limits to adaptation. The present physical barrier to snowmaking is the number of nights with suitable temperature and humidity. Unfortunately for the industry, projections of temperature change in the Australian Alps (Hennessy et al. 2008) suggest that climate change will eliminate this environmental window for snowmaking even if the soft economic limit to water supply was overcome. This hard ecological limit means that the Australian ski tourism industry seems likely to be casualty of climate change.

\section{Coorong, Murray Mouth, and Lakes Alexandrina and Albert} (Coorong and Lakes)

Multiple stresses affect these wetlands of international importance, and these will be further exacerbated by climate change (Gross et al. 2011). The environment has changed, driven by prehistoric natural processes and recent natural and human processes, including the construction of major water storages and barriers, both upstream and onsite, to intercept water for human use (Kingsford et al. 2011). In the Coorong and Lakes, there are a variety of actual and proposed adaptation strategies, with allocations of water central to most. Local communities propose that increased environmental flows of water should support the freshwater ecology of the two lakes and sustain local business and agricultural enterprises. The major constraint to this adaptation is the demand for water from upstream communities for irrigation, who consider environmental flows as a barrier to meet their adaptation goals. The trade-off between these two water uses is not new, but the problem becomes more acute with declining runoff due to climate change.

In this region adaptation to climate change is impeded by the inability of governments and communities to collectively negotiate trade-offs between long-term adaptation goals and strategies that account for the full spectrum of needs and interests. Australia has a long history of managing climatic and hydrological variability, recently establishing a market for water entitlements and strategies to buy back water entitlements and manage water for the environment. Nationally, governments have invested more than $\$ \mathrm{~A} 10$ billion in the buyback of environmental water, including some increasing flows to the Coorong and Lower Lakes. However, conflicts persist. Dealing with the long-standing problem of overextraction of water in the Murray-Darling Basin has not only pitted communities against governments and their agencies, but also has exacerbated upstream-downstream finger pointing about water use. Water buyback strategies have encountered opposition in upstream irrigation areas with people concerned about stranded irrigation assets, and in communities that are less viable, both socially and financially (Pittock and Connell 2010, Gross and Dumaresq 2014).

Overall, there has been progress toward changes that can serve the adaptation requirements of multiple users of the water of the Coorong and Lakes. Still, there remains a tendency for upstream users to prevail in allocation institutions, with downstream groups often having less capacity to influence water management decisions, which can be path dependent and immutable Depending on the point of view of different actors in this system, these are either barriers or soft limits to adaptation in the Coorong and Lakes.

\section{The Great Barrier Reef}

There are barriers and limits to sustaining the reef-based fishing and tourism industries. Scenarios of future change and response were developed with stakeholders, identifying a range of adaptation strategies for both industries (Evans et al. 2013). Three themes were common to adaptation: better stewardship of the reef to enhance its resilience; improvements in business operations, such as forecasting, financial management, marketing, and networking, to enable firms to adapt to climate changes in the reef and commercial environment; and diversification of current and alternative income sources, including fisheries sectors, water-based activities, and reef-based tourism. These adaptation strategies attempt to push back the hard ecological limits from coral bleaching, ocean acidification, high nutrient loads, and fisheries pressures to avoid regime shifts in coral and fisheries (Graham et al. 2015), while seeking to adapt 
local enterprises to avoid significant impacts on livelihoods and local communities if ecological limits are reached.

There are barriers to most of these adaptation strategies, and limits to some. For example, alternative marketing (green, buy local, organic) is perceived as a key adaptation strategy, but its effectiveness is constrained by the somewhat negative reputations of fishing industries and by intense market competition in both fisheries and reef-based tourism. Fisheries industries are attempting to control their reputations through marketing, thereby improving reputations and shifting the barrier. In contrast, the barriers associated with competition from international markets are seen by stakeholders to cause limits to adaptation. They are largely beyond the control of local industries, particularly given the long-term trend of declining industry protection in Australia and the floating Australian dollar. Importantly, there is a perceived interaction between how well competitors in other locations could adapt to climate change, potentially providing a competitive advantage to those industries that are better able to manage their ecosystems in the face of climate change. In globally oriented industries, some soft limits to adaptation are transmitted through markets. The adaptation strategies of reef-based tourism and fishing industries may be limited by their inability to remain competitive in the global markets on which they depend, if and when the hard ecological limits to adaptation on reefs are reached.

\section{Macquarie Marshes}

Climate change poses risks to the ecological values of the Macquarie Marshes (Jenkins et al. 2011). The Macquarie Marshes is a large floodplain and a wetland of international importance under the Ramsar Convention. It is typical of many large floodplains that lie at the ends of large river systems and are regulated by upstream water resource developments, e.g., large dams and diversions of water, in that half or more of the water that used to reach such large wetlands is now diverted. In the case of the Macquarie River, such diversions are predominantly for irrigated agriculture. There is a reasonably linear relationship between reductions in flow and area of wetland lost or degraded in such large floodplains. Climate change is projected to alter flooding extent, frequency, and duration, although for Australia it is not yet clear whether flood risk will increase or decrease, or where and when this might happen. In any case, whatever level of climate impact eventuates, it still remains dwarfed by the effects of river regulation, and so the key barrier, and potential limit, to climate adaptation is how much water can be returned to the wetland.

Thus far, government investments in conservation through declaration of wetland areas in a protected area network have routinely failed, because incoming flows to the Macquarie Marshes have continued to decline. The buyback of water for environmental flows has certainly assisted, with the environmental flows to the Macquarie Marshes almost doubling from 2000 to 2013. Nevertheless, adaptation to sustain the ecological systems of the marshes is a function of managing competing demand for water between upstream and downstream users, and the influence of upstream users in decision making is the most important social barrier to adaptation. As with the Coorong and Lakes, there is a path dependency in water management that casts into doubt a classification of these governance problems as barriers. Although there may be slow changes in water governance, downstream uses, especially ecological uses, see few benefits from theses changes, and upstream uses, especially irrigation uses, predominate. History suggests that the potential for further change in river management that is required for ecological resilience may not be realized, operating as a deep governance driver of the ecological limits to adaptation in the Macquarie Marshes.

\section{Small inland communities}

There are opportunities, barriers, and limits associated with market-based instruments for adapting to drought and water shortages in small inland communities in the Murray-Darling Basin (Kiem and Austin 2012, 2013, Kiem 2013). Water trading has potential as a climate change adaptation strategy, with "cap and trade," quantity-based approaches likely to lead to a reallocation of water to high-value uses such as for mining, manufacturing, and electricity production, resulting in a more efficient allocation of water across the basin.

However, the scale of analysis matters, and the adaptation opportunities associated with market-based instruments have their costs. As the Coorong Lakes and Macquarie Marshes studies show, more efficient allocation in economic terms does not address the adaptation needs of downstream ecosystems and users that depend on them. Indeed, more efficient production with the goal of increasing the value of output across the basin may mean even more diversion of water away from downstream, lower value, and nonmarket uses, with negative environmental and social impacts. Only environmental flows are an adaptation against this, but as water is directed toward higher value uses, and if climate change reduces runoff, the opportunity costs of environmental flows increase, intensifying the political pressure to reduce them. Further, many of the high-value uses of water have high greenhouse gas emissions concentrations per unit of production, creating the risk of maladaptation (Barnett and $\mathrm{O}^{\circ}$ Neill 2010). Therefore, there remains significant uncertainty about the impacts of water trading on the environment, and there is a risk of social impacts in small irrigator communities arising from the forgone "low-value" uses of water, which will mostly be for agricultural purposes.

This study on the use of market-based instruments to advance adaptation highlights the trade-offs in resource allocation, clearly evident in the Coorong and Lakes and Macquarie Marshes cases. The use of markets, as opposed to regulation, moral suasion, or any other policy instrument, does not avoid the politics of adaptation. These cases point to failures in governance as barriers to adaptation, at least as far as downstream ecological uses and most small communities are concerned. However, insofar as these governance issues are persistent and only slowly changing at the margins, they are perhaps soft limits more than barriers to adaptation.

\section{Torres Strait communities}

There were limits to climate change adaptation in the 2 of the Torres Strait's 18 island communities that we studied: Boigu, a low island already inundated by the sea during high spring tides and storm surges, and Erub, a community located on a volcanic high island, but where most settlements lie on the low coastal fringe (McNamara et al. 2011). Torres Strait Islanders are "Saltwater People," marine specialists with worldviews and 
everyday practices that focus on the marine environment (McNiven 2004), including a deep mythological and spiritual relationship with the sea and land (McNiven 2004). Climate changes that degrade ecosystem quality will significantly affect the cultures, identity, and psychosocial well-being of Torres Strait Islanders. The costs of such impacts cannot be understated, nor adequately compensated.

On Boigu, very slow progress on the funding and construction of coastal defenses is consistently identified as a major barrier to adaptation because engineered shoreline protection is seen as critical to the future of this island community. The barrier here is the timeliness of government responses, an enduring problem for Torres Strait Islanders. More broadly, the history of relations between indigenous people and the Queensland and Australian governments does not augur well for a timely response to sea level rise. The history of dispossession, displacement, discrimination, and under-resourcing of indigenous communities in Australia speaks to a path dependence where investments to engineer shorelines may never be forthcoming, or too slow, making this barrier seem more like a limit when viewed historically.

For their part, the community on Erub believed there were few immediate limits to adaptation because the topography of the high island afforded potential for retreat to higher ground. However, participants from coastal villages were concerned that this possibility may itself be a barrier, leading decision makers to discount alternatives that might allow them to remain in their traditional coastal lands. Underlying these concerns about the barriers to infrastructure responses and governmental capability are local peoples' anxieties about the potential for climate change to diminish the cultural and spiritual connections to place that are central to their heritage and identity.

\section{KEY FINDINGS}

A synthesis of these results (Table 3) gives rise to four key findings. These findings further confirm previous studies, but also advance knowledge about the deep drivers of barriers and limits to adaptation.

First, as in many previous studies (Abel et al. 2011, Mukheiber et al. 2013, Marshall and Stokes 2014b), many barriers and soft limits to adaptation arise from processes that occur across scales and spatial domains. Upstream uses of water reduce flows for maintenance of ecological values of the wetlands and the social values they support. Local decision makers seeking ways to adapt have little power over the institutions and industries that create demand and influence the management and use of water upstream. This is true too for inland towns and small farming communities: farmers report frustration at their inability to influence the design of water markets, at the uncertainties associated with the constantly changing rules of these markets, and at the activities of large institutional players in these markets. The processes that constrain adaptation are sometimes global. The limits to adaptation in tourism in the Great Barrier Reef and alpine areas partly arise from global competition from emerging tourism destinations and the higher costs associated with visiting Australia. These processes reduce demand and affect profitability, constraining investments in adaptation actions. These processes, which are often beyond the control of local actors, are not practically mutable and are better conceived of as soft limits to adaptation.
Our second key finding strongly supports other studies that find that trade-offs in the allocation of resources in response to perceived scarcities that are seen as barriers are perhaps ultimately limits to adaptation for some actors and sectors. For example, in a drying climate, there will be increased competition for water between the environment and uses such as ski fields, irrigation, power, mining, and potable water for public supply. Where water is scarce, decisions about its allocation will necessarily require trade-offs among demands, and decisions are highly influenced by strong stakeholder groups. Further, in creating markets as distributional mechanisms, the economic value of water is given preference over its ecological and cultural values because water is allocated to those who can afford to pay the most for it. Therefore, adaptation goals that rely on water are also traded off: users that can pay for water can adapt; users that cannot pay, or cannot otherwise influence the allocation of water, face limits to adaptation. In the Australian Alps there are emerging trade-offs between ski resorts, which may adapt for some time by moving to more elevated areas, and conservation objectives that would be adversely affected by this move. In the Great Barrier Reef, too, there are trade-offs between the resilience of the reef ecosystem, underpinning successful adaptation by reef industries, and adaptation by land-based actors

There is merit in making explicit these trade-offs between adaptation goals and the resulting distribution of outcomes. When adaptation reaches its limits, valued assets will be lost and this needs to be understood widely. When those limits arise because of trade-offs in which the interests of some groups prevail over the interests of others, then adaptation becomes a matter of social justice. For example, small inland towns and wetlands, together with their environmental and cultural values, may lose if agricultural producers adapt through increasing water use; reef ecosystems and the tourism and fisheries industries that depend on them could lose if farmers in the coastal hinterland adapt through intensification and increased application (and runoff) of fertilizers and pesticides; conservation efforts to enhance ecosystem resilience in the Australian Alps are threatened by expansion and diversification of previously ski/snow-based tourism resorts; and the unique cultures and livelihoods of people in the Torres Strait will be degraded if government assistance for coastal protection is not forthcoming.

Identifying and discussing the trade-offs associated with adaptation decisions in advance can help focus attention on potential winners and losers from climate change adaptation, reveal public preferences with respect to acceptable and unacceptable losses, and stimulate thinking about changes to avoid making trade-offs. Failure to identify these trade-offs will mask the power of existing institutions and interests in adaptation processes, will marginalize less powerful groups, and may lead to climate change impacts that the public finds morally unacceptable. Theories of justice advise that choices between what to protect and what to let go should be made explicit and should be the subject of deliberation by stakeholders (Gross 2014). In this way, adaptation can arise through active, and admittedly sometimes hard, choices rather than de facto and mostly hidden institutional processes.

Our third key finding is an empirical substantiation of an otherwise largely hypothesized point in the literature (e.g., Klein 
Table 3. Summary of results from six case studies.

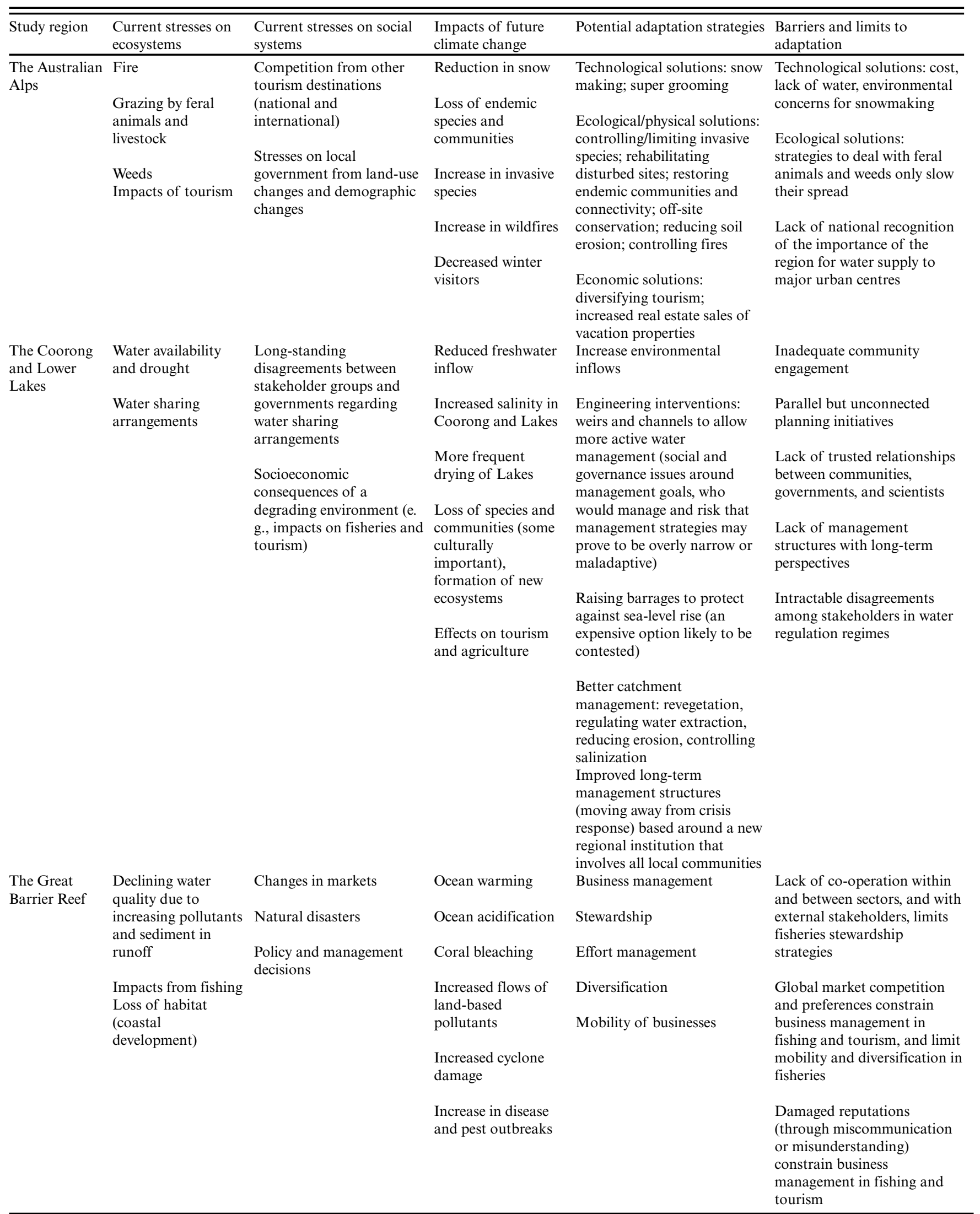




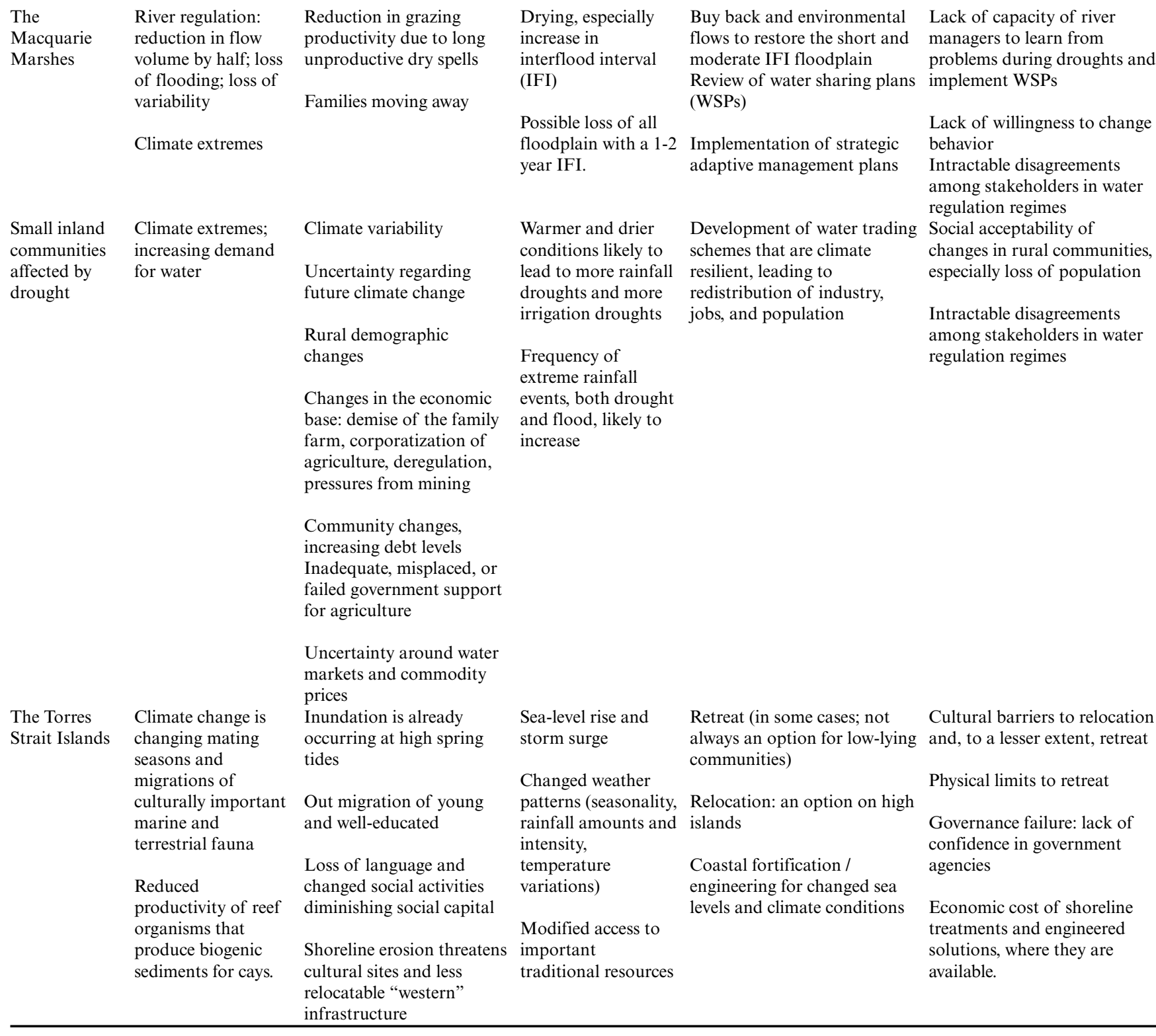

et al 2014), which is that barriers to adaptation can become limits. Although barriers can be theoretically overcome with concerted effort (Moser and Ekstrom 2010), precedence suggests that such effort seems highly unlikely for many communities in our cases. For example, the economic barrier to the strategy of coastal protection in the Torres Strait and the political and policy barriers to allocating sufficient water to wetlands were perceived more as soft limits rather than malleable barriers. The limits to adaptation arise from an inability of institutions to adjust in time to avoid crossing physical thresholds, even if such adjustments seem theoretically possible. This finding suggests that there is considerably more interplay between barriers and limits in practice that has been hitherto realized. It is often said that many barriers to adaptation are institutional, implying that they are socially created and so within our power to remove; however, this can mask the reality that there is a strong probability that many will never be overcome.
This related to our fourth key finding, which speaks to recent calls for research identifying underlying drivers of the barriers and limits to adaptation (Biesbroek at al. 2013, Eisenack et al. 2014). Many of the institutions that constrain adaptation are path dependent. For example, water management institutions have evolved to meet the expectations to supply tens of thousands of users, developed over many decades, and this assemblage of rules, norms, infrastructure, and communities is hard to change. Similarly, the high capital cost of investment in water infrastructure in the river systems that supply the Coorong and Lakes wetlands and Macquarie Marshes makes it less likely that alternative options will be adopted. In the Torres Strait islands, history suggests that a timely and adequate investment in adaptation across all affected communities seems unlikely. In Australia at least, adaptation therefore seems to be constrained by the same factors that constrain effective governance on many policy issues, including natural resource management. In this 
sense, barriers to adaptation stem from the very nature of governance institutions, which is unsurprising because institutions are by definition enduring forms of social organization that do not easily change (see Dovers and Hezri 2010).

This finding about path dependency as an underlying driver of barriers and ultimately limits reinforces Abel and colleagues ' (2011) study of adaptation on the coast in Queensland, which found that development and population growth are higher order policy goals that increasingly necessitate coastal protection, and that increasing defensive works reduces the scope for other adaptation strategies. A similar pattern of path dependency is identified by Macintosh and colleagues (2014), who argue that governance structures and property institutions in Australia are path dependent and selfperpetuating in situations where changing them involves significant transaction costs; thus, inertia and system reproduction result. Finally for urban water, Barnett and O'Neill (2010) argue that a history of increasing supply as a response to urban water scarcity leads to desalinization plants becoming the solution to climateinduced water stress and that such decisions only reinforce supplyside measures at the cost of alternatives such as reducing demand. These and our six cases all cast into doubt the classification of long-standing institutional problems as barriers to adaptation. History suggests they are not amenable to change without concerted effort. At least from the perspective of people and groups that have been waiting for changes that never materialize, longstanding institutional problems may instead be better understood as soft limits to adaptation.

\section{CONCLUSIONS}

Adapting to climate change requires changes in the way societies are organized. Our six case studies suggest that the difference between barriers and limits to such changes is a matter of spatiotemporal perspective: the possibility of mutable constraints seems more or less likely depending on where one sits, and on how one understands history. The institutions that structure vulnerability persist for a reason and reproduce themselves over time. Such path dependency structures social vulnerability, creates patterns in trade-offs among adaptation actions, and inhibits changes for adaptation. To say that the barriers and limits to climate change are most often socially constructed is not to say that they can be easily reconstructed. If such changes are slower in the making than climate change, then there will be many limits to adaptation. It is in this context that the concept of transformation takes on added significance. For it may only be when there are radical changes in the governance of public goods and markets, that there is push back of the limits to adaptation for many of the most vulnerable people and places.

Responses to this article can be read online at: http://www.ecologyandsociety.org/issues/responses. $\mathrm{php} / 7698$

\section{Acknowledgments:}

The studies described in this paper were funded by the Australian government through the National Climate Change Adaptation Research Facility.

\section{LITERATURE CITED}

Abel, N., R. Goddard, B. Harman, A. Leitch, J. Langridge, A. Ryan, and S. Heyenga. 2011. Sea level rise, coastal development and planned retreat: analytical framework, governance principles and an Australian case study. Environmental Science \& Policy 14:279-288. http://dx.doi.org/10.1016/j.envsci.2010.12.002

Adger, W. N., S. Agrawala, M. Mirza, C. Conde, K. O’Brien, J, Pulhin, R. Pulwarty, B. Smit, and K. Takahashi. 2007. Assessment of adaptation practices, options, constraints and capacity. Pages 717-743 in M. Parry, O. Canziani, J. Palutikof, P. van der Linden, and C. Hanson, editors. Climate change 2007: impacts, adaptation and vulnerability. Contribution of Working Group II to the Fourth Assessment Report of the Intergovernmental Panel on Climate Change. Cambridge University Press, Cambridge, UK

Adger, W. N., S. Dessai, M. Goulden, M. Hulme, I. Lorenzoni, D. R. Nelson, L. O. Naess, J. Wolf, and A. Wreford. 2009a. Are there social limits to adaptation to climate change? Climatic Change 93:335-354. http://dx.doi.org/10.1007/s10584-008-9520$\underline{Z}$

Adger, W. N., I. Lorenzoni, and K. O'Brien, editors. $2009 \mathrm{~b}$. Adapting to climate change: thresholds, values, governance. Cambridge University Press, Cambridge, UK.

Barnett, J. 2009. Human rights and vulnerability to climate change. Pages 257-271 in S. Humphreys, editor. Human rights and climate change. Cambridge University Press, Cambridge, UK. http://dx.doi.org/10.1017/cbo9780511770722.011

Barnett, J., and S. O'Neill. 2010. Maladaptation. Global Environmental Change 20:211-213. http://dx.doi.org/10.1016/j. gloenvcha.2009.11.004

Biesbroek, G. R., J. E. M. Klostermann, C. J. A. M. Termeer, and P. Kabat. 2013. On the nature of barriers to climate change adaptation. Regional Environmental Change 13:1119-1129. http:// dx.doi.org/10.1007/s10113-013-0421-y

Burch, S. 2010. Transforming barriers into enablers of action on climate change: insights from three municipal case studies in British Columbia, Canada. Global Environmental Change 20:287-297. http://dx.doi.org/10.1016/j.gloenvcha.2009.11.009

Dovers, S. R., and A. A. Hezri. 2010. Institutions and policy processes: the means to the ends of adaptation. Wiley Interdisciplinary Reviews: Climate Change 1:212-231. http://dx. doi.org/10.1002/wcc. 29

Dow, K., F. Berkhout, B. L. Preston, R. J. T. Klein, G. Midgely, and M. R. Shaw. 2013a. Limits to adaptation. Nature Climate Change 3:305-307. http://dx.doi.org/10.1038/nclimate1847

Dow, K., F. Berkhout, and B. L. Preston. 2013b. Limits to adaptation to climate change: a risk approach. Current Opinion in Environmental Sustainability 5:384-391. http://dx.doi. org/10.1016/j.cosust.2013.07.005

Eckstrom, J. A., and S. C. Moser. 2014. Identifying and overcoming barriers in urban climate adaptation: case study findings from the San Francisco Bay Area, California, USA. Urban Climate 9:54-74. http://dx.doi.org/10.1016/j.uclim.2014.06.002

Eisenack, K., S. C. Moser, E. Hoffmann, R. J. T. Klein, C. Oberlack, A. Pechan, M. Rotter, and C. J. A. M. Termeer. 2014. Explaining and overcoming barriers to climate change 
adaptation. Nature Climate Change 4:867-872. http://dx.doi. org/10.1038/nclimate2350

Eriksen, S., P. Aldunce, C. S. Bahinpati, R. D. Martins, J. I. Molefe, C. Nhemachena, K. O'Brien, F. Olorunfemi, J. Park, L. Sygna, and $\mathrm{K}$. Ulsrud. 2011. When not every response to climate change is a good one: identifying principles for sustainable adaptation. Climate and Development 3:7-20. http://dx.doi.org/10.3763/ $\underline{\text { cdev. } 2010.0060}$

Evans, L. S., P. Fidelman, C. Hicks, C. Morgan, A. L. Perry, and $\mathrm{R}$. Tobin. 2011. Limits to climate change adaptation in the Great Barrier Reef: scoping ecological and social limits. National Climate Change Adaptation Research Facility, Gold Coast, Australia. [online] URL: http://www.nccarf.edu.au/publications/limits-adaptationgreat-barrier-reef

Evans, L. S., C. C. Hicks, P. Fidelman, R. C. Tobin, and A. L. Perry. 2013. Future scenarios as a research tool: investigating climate change impacts, adaptation options and outcomes for the Great Barrier Reef, Australia. Human Ecology 41(6):841-857. http://dx. doi.org/10.1007/s10745-013-9601-0

Fankhauser, S. 2010 The costs of adaptation. Wiley Interdisciplinary Reviews: Climate Change 1:23-30. http://dx.doi. org/10.1002/wcc. 14

Garrelts, H., and H. Lange. 2011. Path dependencies and path change in complex fields of action: climate adaptation policies in Germany in the realm of flood risk management. Ambio 40:200-209. http://dx.doi.org/10.1007/s13280-010-0131-3

Graham, N. A. J., S. Jennings, M. A. MacNeil, D. Mouillot, and S. K. Wilson. 2015. Predicting climate-driven regime shifts versus rebound potential in coral reefs. Nature 518:94-97. http://dx.doi. org/10.1038/nature 14140

Gross, C. 2014. Fairness and justice in environmental decisionmaking: water under the bridge. Routledge, Oxford, UK.

Gross, C., and D. Dumaresq. 2014. Taking the longer view: timescales, fairness and a forgotten story of irrigation in Australia. Journal of Hydrology 519(part C):2483-2492. http://dx.doi. org/10.1016/j.jhydrol.2014.08.056

Gross, C., J. Pittock, M. Finlayson, and M. C. Geddes, 2011. Climate change adaptation in the Coorong, Murray Mouth and Lakes Alexandra and Albert. National Climate Change Adaptation Research Facility, Gold Coast, Australia. [online] URL: http:// www.nccarf.edu.au/publications/limits-adaptation-coorong-murrayalexandrina-albert

Hennessy, K. J., P. H. Whetton, K. Walsh, I. N. Smith, J. M. Bathols, M. Hutchinson, and J. Sharples. 2008. Climate change effects on snow conditions in mainland Australia and adaptation at ski resorts through snow making. Climate Research 35:255-270. http:// dx.doi.org/10.3354/cr00706

Hodgkinson, J. H., A. J. Hobday, and E. A. Pinkard. 2014. Climate adaptation in Australia's resource-extraction industries: ready or not? Regional Environmental Change 14:1663-1678. http://dx.doi. org/10.1007/s10113-014-0618-8

Hurlimann, A., J. Barnett, R. Fincher, N. Osbaldiston, C. Mortreux, and S. Graham. 2014. Urban planning and sustainable adaptation to sea-level rise. Landscape and Urban Planning 126:84-93. http://dx.doi.org/10.1016/j.landurbplan.2013.12.013
Inderberg, T. H. 2011. Institutional constraints to adaptive capacity: adaptability to climate change in the Norwegian electricity sector. Local Environment 16:303-317. http://dx.doi. org/10.1080/13549839.2011.569538

Islam, M. M., S. Sallu, K. Hubacek, and J. Paavola. 2014. Limits and barriers to adaptation to climate variability and change in Bangladeshi coastal fishing communities. Marine Policy 43:208-216. http://dx.doi.org/10.1016/j.marpol.2013.06.007

Jenkins, K. M., R. T. Kingsford, B. J. Wolfenden, S. Whitten, H. Parris, C. Sives, R. Rolls, and S. Hay. 2011. Limits to climate change adaptation in floodplain wetlands: the Macquarie Marshes. National Climate Change Adaptation Research Facility, Gold Coast, Australia. [online] URL: http://www.nccarf.edu.au/publications/ $\underline{\text { limits-adaptation-floodplain-wetlands-macquarie-marshes }}$

Kiem, A. S. 2013. Drought and water policy in Australia: challenges for the future illustrated by the issues associated with water trading and climate change adaptation in the Murray-Darling Basin. Global Environmental Change 23:1615-1626. http://dx.doi. org/10.1016/j.gloenvcha.2013.09.006

Kiem, A. S., and E. K. Austin. 2012. Limits and barriers to climate change adaptation for small inland communities affected by drought. National Climate Change Adaptation Research Facility, Gold Coast, Australia. [online] URL: http://www.nccarf.edu.au/ publications/limits-adaptation-small-inland-communities-drought

Kiem, A. S., and E. K. Austin. 2013. Drought and the future of rural communities: opportunities and challenges for climate change adaptation in regional Victoria, Australia. Global Environmental Change 23:1307-1316. http://dx.doi.org/10.1016/j.gloenvcha.2013.06.003

Kingsford, R. T., K. F. Walker, R. E. Lester, W. J. Young, P. G. Fairweather, J. Sammut, and M. C. Geddes. 2011. A Ramsar wetland in crisis - the Coorong, Lower Lakes and Murray Mouth, Australia. Marine \& Freshwater Research 62:255-265. http://dx.doi. org/10.1071/MF09315

Klein, R. J. T., G. F. Midgley, B. L. Preston, M. Alam, F. G. H. Berkhout, K. Dow, and M. R. Shaw. 2014. Adaptation opportunities, constraints, and limits. Pages $899-943$ in C. B. Field, V. R. Barros, D. J. Dokken, K. J. Mach, M. D. Mastrandrea, T. E. Bilir, M. Chatterjee, K. L. Ebi, Y. O. Estrada, R. C. Genova, et al. editors. Climate change 2014: impacts, adaptation and vulnerability. Part A: Global and sectoral aspects. Contribution of Working Group II to the Fifth Assessment Report of the Intergovernmental Panel on Climate Change. Cambridge University Press, Cambridge, UK.

Macintosh, A. 2012. Coastal climate hazards and urban planning: how planning responses can lead to maladaptation. Mitigation and Adaptation Strategies for Global Change 18:1035-1055. http://dx. doi.org/10.1007/s11027-012-9406-2

Macintosh, A., A. Foerster, and J. McDonald. 2014. Policy design, spatial planning and climate change adaptation: a case study from Australia. Journal of Environmental Planning and Management 58:1432-1453. http://dx.doi.org/10.1080/09640568.2014.930706

Marshall, N., and C. J. Stokes. 2014a. Identifying thresholds and barriers to adaptation through measuring climate sensitivity and capacity to change in an Australian primary industry. Climatic Change 126:399-411. http://dx.doi.org/10.1007/s10584-014-1233$\underline{\mathrm{x}}$ 
Marshall, N. A., and C. J. Stokes. 2014b. Influencing adaptation processes on the Australian rangelands for social and ecological resilience. Ecology and Society 19(2): 14. http://dx.doi. org/10.5751/ES-06440-190214

McDonald, J. 2007. A risky climate for decision-making: the liability of development authorities for climate change impacts. Environmental and Planning Law Journal 24:405-416.

McNamara, K. E., S. G. Smithers, R. Westoby, and K. Parnell. 2011. Limits to climate change adaptation for low-lying communities in the Torres Strait. National Climate Change Adaptation Research Facility, Gold Coast, Australia. [online] URL: http://www.nccarf.edu.au/publications/limits-adaptationlow-lying-communities-torres-strait

McNiven, I. 2004. Saltwater people: spiritscapes, maritime rituals and the archaeology of Australian indigenous seascapes. World Archaeology 35:329-349. http://dx.doi.org/10.1080/0043824042000185757

Measham, T. G., B. L. Preston, T. F. Smith, C. Brooke, R. Goddard, G. Withycombe, and C. Morrison. 2011. Adapting to climate change through local municipal planning: barriers and challenges. Mitigation and Adaptation Strategies for Global Change 16:889-909. http://dx.doi.org/10.1007/s11027-011-9301-2

Meinshausen, M., N. Meinshausen, W. Hare, S. C. B. Raper, K. Frieler, R. Knutti, D. J. Frame, and M. R. Allen. 2009. Greenhouse-gas emission targets for limiting global warming to $2^{\circ} \mathrm{C}$. Nature 458:1158-1162. http://dx.doi.org/10.1038/nature08017

Morrison, C., and C. Pickering. 2011. Climate change adaptation in the Australian Alps: impacts, strategies, limits and management. National Climate Change Adaptation Research Facility, Gold Coast, Australia. [online] URL: http://www.nccarf.edu.au/ publications/limits-adaptation-climate-change-adaptation-australianalps

Morrison, C., and C. M. Pickering. 2013a. Limits to climate change adaptation: case study of the Australian Alps. Geographical Research 51:11-25. http://dx.doi.org/10.1111/ j.1745-5871.2012.00758.x

Morrison, C., and C. M. Pickering. 2013b. Perceptions of climate change impacts, adaptation and limits to adaption in the Australian Alps: the ski-tourism industry and key stakeholders. Journal of Sustainable Tourism 21:173-191. http://dx.doi. org/10.1080/09669582.2012.681789

Moser, S. C., and J. A. Ekstrom. 2010. A framework to diagnose barriers to climate change adaptation. Proceedings of the National Academy of Sciences of the United States of America 107:22026-22031 http://dx.doi.org/10.1073/pnas.1007887107

Mukheiber, P., N. Kuruppu, A. Gero, and J. Herriman. 2013. Overcoming cross-scale challenges to climate change adaptation for local government: a focus on Australia. Climatic Change 121:271-283. http://dx.doi.org/10.1007/s10584-013-0880-7

Palutikof, J., J. Barnett, and D. Guitart. 2014a. Can we adapt to four degrees of warming? Yes, no and maybe.... Pages 216-233 in P. Christoff, editor. Four degrees of global warming: Australia in a hot world. Routledge, Abingdon, UK.

Palutikof, J. P., J. Barnett, S. L. Boulter, and D. Rissik. $2014 b$. Adaptation as a field of research and practice: notes from the frontier of adaptation. Pages 6-20 in J. P. Palutikof, S. L. Boulter, J. Barnett, and D. Rissik, editors. Applied studies in climate adaptation. Wiley, Chichester, UK. http://dx.doi. org/10.1002/9781118845028.ch2

Park, S. E., N. A. Marshall, E. Jakku, A. M. Dowd, S. M. Howden, E. Mendham, and A. Fleming. 2012. Informing adaptation responses to climate change through theories of transformation. Global Environmental Change 22:115-126. http://dx.doi. org/10.1016/j.gloenvcha.2011.10.003

Pickering, C. M., and R. C. Buckley. 2010. Climate response by ski resorts: the shortcomings of snowmaking for Australian resorts. Ambio 39:430-438. http://dx.doi.org/10.1007/s13280-010-0039y

Pittock, J., and D. Connell. 2010. Australia demonstrates the planet's future: water and climate in the Murray-Darling Basin. International Journal of Water Resources Development 26:561-578. http://dx.doi.org/10.1080/07900627.2010.519522

Preston, B. L., C. Brooke, T. G. Measham, T. F. Smith, and R. Gorddard. 2008. Igniting change in local government: lessons learned from a bushfire vulnerability assessment. Mitigation and Adaptation Strategies for Global Change 14:251-283. http://dx. doi.org/10.1007/s11027-008-9163-4

Raymond, C. M., and G. M. Robinson. 2013. Factors affecting rural landholders' adaptation to climate change: insights from formal institutions and communities of practice. Global Environmental Change 23:103-114. http://dx.doi.org/10.1016/j. gloenvcha.2012.11.004

Rickards, L. 2013. Transformation is adaptation. Nature Climate Change 3:690. http://dx.doi.org/10.1038/nclimate1933

Scally, J., and G. Wescott. 2011. Perceptions of climate change and adaptation responses in a local community: the Barwon Estuary Complex, Victoria. Australian Geographer 42:387-401. http://dx.doi.org/10.1080/00049182.2012.619954

Smith, T. F., C. Brooke, T. Measham, B. Preston, R. Goddard, G. Withycombe, B. Beverage, and C. Morrison. 2008. Case studies of adaptive capacity: systems approach to regional climate change adaptation strategies. CSIRO Climate Adaptation Flagship, Sydney, Australia.

Stafford Smith, M., L. Horrocks, A. Harvey, and C. Hamilton. 2011. Rethinking adaptation for a $4^{\circ} \mathrm{C}$ world. Philosophical Transactions of the Royal Society A: Mathematical, Physical and Engineering Sciences 369:196-216. http://dx.doi.org/10.1098/ $\underline{\text { rsta.2010.0277 }}$

Veron, J. E. N. 2011. Ocean acidification and coral reefs: an emerging big picture. Diversity 3(2):262-274 http://dx.doi. org/10.3390/d3020262

Waters, E., J. Barnett, and A. Puleston. 2014. Contrasting perspectives on barriers to adaptation in Australian climate change policy. Climatic Change 124:691-702. http://dx.doi. org/10.1007/s10584-014-1138-8 